\title{
The examination of Pre-university School Boys' Awareness of HIV Prevention, Transmission and Treatment in Khuzestan Province
}

\author{
Masoud Boroumand Nasab \\ Assistant Professor, Department of Psychology , Dezful Branch, Islamic Azad University, \\ Dezful, Iran \\ E-mail address: \\ mohamad_khaledian22@yahoo.com
}

Keywords: awareness; HIV prevention; HIV transmission; HIV treatment

\begin{abstract}
This research aimed to examine pre-university school boys' awareness of the factors in preventing, transmitting and treating HIV in Khuzestan province, Iran. This is a descriptive cross-sectional study. A sample size of 300 was determined using multistage random sampling method. The data were collected through a questionnaire, being analyzed with chi-square test. The research findings show that the students' awareness of HIV prevention and transmission is not desirable, the majority of the population's extent of information being below the expected mean while that of the disease treatment is more favorable. The students' awareness of the methods for HIV prevention and transmission is low.
\end{abstract}

\section{INTRODUCTION}

Social problems arise from a variety of factors, influencing a large group of people from all different walks of life. But what cannot be disregarded is that social issues affect teenagers and the young more than any other age group; the age group building the future of a country and being regarded as a benefit. Of the problems with which all countries have faced in recent decades is AIDS which has killed or crippled millions of people. The young are more likely to be infected by HIV since they are prone to practicing risky sexual behaviors and building relationships with opposite sex on a large scale. So, given that the young are more likely to get this disease across the world, teaching prevention methods for AIDS is the only way to reduce the risk of HIV infection among this age group (1). However, $25.1 \%$ of 15 to 18 year old students have no information about drug abuse. Accordingly and given that Iran is among the 126 countries affected by AIDS, it is important to assess Iranian students, teenagers and adults' awareness of HIV so that short-term and long-term measures are taken for teaching HIV/AIDS prevention methods and skills based on the data obtained. A research on 899 high school students in Bangkok indicated that $99 \%$ of them have information about this disease to some extent; $89 \%$ and only $32.5 \%$ have gained their information through TV and parents respectively (2). Some studies have shown that the level of students' awareness, especially those in the countries affected by the epidemic, is low (3). A few studies have suggested that there is a direct relationship between the level of awareness and degree level and with increasing age comes the increased level of awareness of the illness; the students at a higher level of education have more information about HIV/AIDS $(2 ; 4)$. The results of a research carried out in 40 countries indicate that more than $50 \%$ of 15 to 24 year old people have had misconceptions about how HIV/AIDS is transmitted (5). In another study conducted on some Japanese female students, $12.5 \%$ of them said that HIV/AIDS is transmitted by mosquito bites (6).

The results of a research done in Malaysia revealed that most students had a high awareness of HIV transmission routes; however their knowledge about other ways of transmission, such as tattooing and sexual contact was low. In addition, majority of the students knew that HIV is not transmitted through mosquito bites and swimming pools (7).

Studies conducted in Iran have indicated that Tehrani students' awareness of AIDS, of HIV transmission, and of prevention ways were 77.5\% (good), 90\% (good), 48.5\% (average) and 50.8\% (average) respectively (8). 
The results of a research on female high school students with regard to AIDS in Kazerun showed that $89.47 \%$ of them regarded the cause to be a virus and $81.57 \%$ said that this disease can be diagnosed by blood test and $62.26 \%$ also knew that AIDS could not be cured. $87.36 \%, 85.26 \%$, $76.31 \%$ and $66.31 \%$ were aware of HIV transmission routes; sexual contact, intravenous drug abuse, blood transfusion and mother-to-child transmission respectively. But only $46.84 \%$ of the students knew that only one sexual contact could transmit the virus. The role of sexual contact and intravenous drug abuse is better known than that of the number of sexual partners and heterosexuality. $47.36 \%$ of the students have been aware of the relationship between AIDS and sexually transmitted diseases but only $4.2 \%$ could mention three sexually transmitted diseases (9). A research examined the level of students' awareness of HIV/AIDS transmission and prevention ways in Yazd province high schools, the results of which showed that their awareness with regard to mother-to-child transmission, sexual contact, and transmission through needlestick injury and contaminated razor blades was $46.3 \%$, sexual intercourse, needlesticks and contaminated razor blades, and sexual intercourse, mother-to-child transmission, contaminated razor blades and saliva was $36.6 \%$ and $2.4 \%$ respectively. AIDS prevention methods awareness score (preventing from illegal sexual contacts, using disposable needles and syringes) and the score through preventing from having sexual contacts and personal hairdressing items were $34.1 \%$ and $9.8 \%$ respectively (10).

\section{METHODOLOGY}

\section{Participants and sampling method}

This is a descriptive cross-sectional research. The statistical population included all students of boys' pre-university schools in Khuzestan province. The research sample consisted of 300 people who were selected out of 17-21 year old students using multistage random sampling method.

\section{Instruments}

In this research, the data were collected using a questionnaire. The initial questionnaire was obtained using the texts related to the disease and AIDS experts' opinions. The analysis of the experts' opinions showed that there was an $81 \%$ agreement. Then, in order to determine validity and reliability, the questionnaire was administered to a sample of students. Reliability coefficient was found to be 0.91 using Cronbach's alpha. Concurrent validity was used to determine validity. For this purpose, a criterion-based questionnaire was drawn upon. This questionnaire was developed based on the incorporation of Khosrow Panah's questionnaire (11) and Nojoumi et al questionnaire (8). The mixture of these questionnaires measured prevention, transmission and treatment.

\section{RESULTS}

This research proposes three questions with regard to prevention, transmission and treatment of AIDS:

$1^{\text {st }}$ question: Are pre-university male high schoolers familiar with AIDS prevention methods?

As table 1 shows, the frequency of the participants who have answered appropriately and that of the subjects who have replied inappropriately are 118 and 181 respectively. The obtained $\mathrm{x}^{2}$ is equal to 13.274, which is significant at a level of $p<0.0001$. In other words, it can be said that the number of the participants who are familiar enough with AIDS prevention ways is significantly lower than those who are not familiar enough with the methods. Therefore, the answer to the first question is negative.

$2^{\text {nd }}$ question: Are pre-university male high schoolers familiar with AIDS transmission routes?

As table 2 shows, the number of the participants who had answered the questions related to AIDS transmission routes appropriately and those answered inappropriately were 130 and 169 respectively. The obtained $x^{2}$ is equal to 5.09, which is significant at a level of $p=0.024$. That is, the number of the participants who are familiar enough with AIDS transmission routes is significantly 
is lower than those who are not familiar enough with the routes. Therefore, the answer to the second question is also negative.

$3^{\text {rd }}$ question: Are pre-university male high schoolers familiar with AIDS treatment ways?

There are 10 questions in regard to the $3^{\text {rd }}$ question of the research to which all subjects have replied. The number of the participants having answered appropriately and inappropriately along with the results obtained from chi-square test have been shown in table 3.

As table 2 shows, the number of the participants who had answered the questions related to the third question appropriately and those answered inappropriately were 135 and 164 respectively. The obtained $\mathrm{x}^{2}$ is equal to 2.81, which is not significant at the expected level. Accordingly, although the number of the students who have answered inappropriately is more than those who have replied appropriately, this difference is not significant at the expected level. So it can be said that there is no significant difference between the number of the students who have answered appropriately and those who have answered inappropriately.

\section{DISCUSSION}

The results obtained from the first question revealed that out of 299 participants, 181 gave inappropriate answers to the question and 118 answered appropriately and there was a significant difference at $p<0.001$. That is; the number of the students who are familiar enough with this matter is significantly below that of the students who are not familiar enough with this matter. So the answer to the first question is negative.

This finding is in agreement with the findings of $(3,4,2,13,14,10$, and 12) although it is inconsistent with some of the studies done with the students (15).

These findings can be explained by the fact that the information provided to the students is not coherent and unified. Some experts believe that misconceptions about AIDS can be a result of common inaccurate rumors and information, providing people, especially the young with accurate information being a necessity (16). It is therefore essential to properly and effectively educate the teenagers and students about the prevention methods for this disease (17).

The results concerning the second question indicated that out of 299 participants, 130 gave appropriate answers to the question and 169 answered inappropriately; a significant difference at $p$ $<0.05$. That is; the number of the students who are not familiar enough with this matter is significantly above that of the students who are familiar enough with this matter. So the answer to the second question is negative.

This finding was consistent with those of $(10,19,11,6,18,17$, and 16) but it was inconsistent with some (4, and 8). These findings can be explained by the fact since some AIDS transmission routes such as homosexual contacts are not specifically dealt with in public broadcasting like radio and television, and in schools and families, and because of some self-censorships and narrowmindedness, instead of addressing main issues (sexual contact, and intravenous drug abuse), routes like mosquito bite, using shared dinnerware or everyday social communications are examined. The myths about AIDS transmission routes is so dangerous that may lead to misinterpretations about HIV-positive patients (20). Given that students and teenagers gain most of their information through radio, TV and Iranian newspapers of public record (12), some researchers argue that, due to the growing effect of sexual misconducts on HIV transmission routes, another medium shall be formed in the society since the above-mentioned mass media act poorly with regard to informing the teenagers about sexual misconducts due to cultural limitations, except in special circumstances, the results showing that most teenagers are unaware of the existence of condoms. Less than $10 \%$ of the subjects named sexual misconducts as the main cause of suffering from this disease and in no interviews, homosexuality has been mentioned as a transmission route. (13).

The results concerning the third question indicated that out of 299 participants, 135 gave appropriate answers to the question and 164 answered inappropriately. Although the number of the students who are not familiar enough with this matter is above that of the students who are familiar enough with this matter, there is no significant difference at a level of $\mathrm{p}<0.05$. 
This result is in line with those of $(22,13$, and 12$)$. This discovery can be explained in this way; this item like the previous ones; transmission and prevention, can be improved by education, a variety of studies having pointed to the role of education in raising public awareness level of AIDS (23). In view of the fact that most teenagers and the young gain their information about AIDS through radio, TV and their parents (21), parents and teachers are usually reluctant to discuss prevention methods and transmission routes. Furthermore, since parents' information about prevention methods is not adequate, they provide their children with inadequate information, for example the majority of teenage girls' mothers, in a study, refer to the safety of vaccines and treatment (21). Additionally, radio and TV and even print media do not supply the readers with detailed information, Wolffers (24) expressing that most media are helpful in introducing AIDS/HIV but unsuccessful in fostering deep awareness about this disease. It can be concluded that students' awareness level of AIDS/HIV prevention and transmission routes it low. So incorporating information about AIDS/HIV and its prevention and transmission routes into high school coursebooks, using health specialists and teachers in order to heighten students' awareness, giving necessary education about AIDS to teachers and school staff are crucial steps in developing students' awareness of AIDS/HIV prevention and treatment.

\section{References}

[1] Khosropanah, M.H. [Study the knowledge of Dezful people on HIV in 2006].;abstract book on $2^{\text {nd }}$ seminar on HIV, from knowledge to Power. Tehran; Rasa publication2006: 2021(Persian).

[2] Ball J. School Based HIV and AIDS Prevention: chalk and Talk is not Enough .React1997, 1: $1-5$.

[3] Mollahosaini, H.F., Nazmie, H., \& Shareghzadeh, H. [Study the knowledge of on of the Yazd High school students on transfection and prevention of HIV]. Regional Seminar of Aids. Islamic Azad University of Khomain branch 2007,313-316(Persian).

[4] Emamhadi,M.A., Jalilvand, M., \& Hadian,M.[ Study the knowledge and attitude of Tehran high school student toward HIV].;Scientific journal of medical organization of I.R.I 2006.24(4):350-357(Persian)..

[5] Ramazankhani, A., Rostami, S., \& Shokrolla, E. [Study the knowledge and attitude of the students of the governmental Tehran's high school toward HIV]. Journal of medical university of Shahid Sadoghi Yazd 2002 .11(1):43(Persian).

[6] Safavibayat, E. [Study the knowledge of Shahed fajr Tehran audience school students toward HIV]. $3^{\text {rd }}$ national seminar on nursing and HIV. Medical university of Shahid Beheshti 2006:81-82(Persian).

[7] Noori, E., Shabani, Z., Syadi,A.R., \& Kazeroni, M. [Study the knowledge and attitude of Rafsanjan medical university students on student toward HIV in 2006].; abstract book of $2^{\text {nd }}$ seminar on HIV. From knowledge to Power. Tehran; Rasa publication 2006: 19(Persian).

[8] Quek JT, Li SC A Study of the Effectiveness of Aids Health Education Intervention among the Adolescent Population of Singapore. Singapore Med Journal 2002 : 43:359-364.

[9] Omidvar, S. [Knowledge and attitude of obstruction and nursing students on HIV].; journal of Babol medical university. Especial issues on medical training articles 2003.2:37-41(Persian).

[10] Ziagharib, A. [Study the student's knowledge of Gillan medical university on HIV]. Unprinted medical doctor thesis 2001. Gillan medical university. (Persian).

[11] GhorbaniG.A,. Mehrabitatavana, A., \& Ataie, R.A. [Study the knowledge of Baghitolla hospital nurses on HIV]; Journal of Military Medicine2006.8 (2). (Persian). 
[12] Tuchinda S , Chotpitayasunondh T, erartkyl A . Knowledge , Mazlomi Mahmoudabad, S., \& Abasishavazi, M. Study the knowledge and attitude of Yazd high school students on HIV;Tabibn Shargh 2006.8(1):53-63(Persian)..

[13] Ahmadnejad, E. [Study the relevant belief and behavior of females(ages 11-18)on HIV in Oromieh]; The Journal of Fundamentals of Mental Health(2006).8(31-32):81-86(Persian)..

[14] Salehi, L,. Salehi, F., \& Shakiba, E .[Training Need assessment of BandarAbas People about HIV]. Abstract book of regional seminar on HIV and copulative disease. Islamic Azad University Khomain branch2007: 79-58. (Persian).

[15] Hammett TM , Norton GD, Kling R . Chian Prevention Drug Users : Finding Froni a Cross Borden Project in Southern Chian and Northern Vietnam . Journal of Urban Health 2005,82 , 4, 34-42.

[16] Wolffers, I . Culture, Media and HIV/AIDS in Asia, Lancet 1997;349:(9044):52-54 .

[17] Singh S. KAP Study on HIV/AIDS, Among Undergraduates. NJ India 2001: 92(12): 275276.

[18] Roy SK, Bagchi S, Bajpayee A, Pal R, Biswas R . study of KAP of the Private Medical practitioners about National Diseas Control programmes . Indian Journal public Health 2005: 49(4): 256-257.

[19] Quek JT , Li SC . A Study of the Effectiveness of AiDS Health Education Intervention among the Adolescent Population of Singapore. Singapore Med Journal 2002: 43:359-364.

[20] Maswanya E , Moji K , Aoyagi K, Yabata Y . Knowledge and Attitude of Towards AIDS Among Female College Students in Nagasaki, Japan Health Edue Res2000 : 15 (1) : 5 - 11 .

[21] Li-Ping,w.Caroline-Kwong,C.Wah-Yun,L \& Nasruddin,J. HIV/AIDS-related knowledge among Malaysian young adults: findings from a nationwide survey. Journal of the International AIDS Society 2008,10,6.

[22] Nojomi,M., Shojaie, H., \& Ameri, M.A. [Student's knowledge on HIV IN 2002].; Hakim research journal2002.6 (3):41-46(Persian).

[23] Tavallali, R. \& Zeyaie, S. [Study the effect of training on information, attitude and function of female high school stud dents toward HIV]. Abstract book of regional seminar on HIV and copulative disease. Islamic Azad University of Khomain branch 2007: 151-167(Persian).

[24] Attitudes and Practices Of Senior High School Students Regarding Human Immunodeficiency Virus Infection. Journal Med Assoc Thailand 1998: 81(2) : 130-135. 